\title{
GROUP BEHAVIORAL THERAPY FOR ADOLESCENTS WITH TIC-RELATED AND NON-TIC-RELATED OBSESSIVE-COMPULSIVE DISORDER
}

\author{
Joseph A. Himle, Ph.D., ${ }^{*}$ Daniel J. Fischer, M.S.W., Michelle L. Van Etten, Ph.D., Amy S. Janeck, Ph.D., \\ and Gregory L. Hanna, M.D.
}

\begin{abstract}
Prior research supports the distinction between tic-related and non-tic-related obsessive-compulsive disorder (OCD) based on phenomenologic, etiologic, and neurobehavioral data. The present study examines whether response to psychosocial treatment differs in adolescents, depending on the presence of comorbid tics. Nineteen adolescents, 12-17 years of age, participated in 7-week, uncontrolled trial of group cognitive-behavioral treatment (CBT) for OCD. Eight of the patients had tic-related and eleven had non-tic-related OCD. The group CBT program included psycho-education, exposure and response prevention, cognitive strategies, and family involvement. Significant improvement was observed for all subjects on the Yale-Brown Obsessive Compulsive Scale ratings of obsessions, compulsions, and total OCD symptoms. Outcomes were similar for subjects with tic-related and non-tic-related OCD. These preliminary results suggest that the presence of comorbid tic disorders may not attenuate response to behavioral group treatment among adolescents.

Depression and Anxiety 17: 73-77, 2003. ㄷ 2003 Wiley-Liss, Inc.
\end{abstract}

Key words: obsessive-compulsive disorder; behavior therapy; tics; adolescents

\section{INTRODUCTION}

O bsessive-compulsive disorder (OCD) has been found to co-occur with tic disorders. Nearly $60 \%$ of children and adolescents with OCD will develop tics at some point in their lives [Leonard et al., 1992]. Leckman and colleagues [Leckman et al., 2000] coined the terms tic-related and non-tic-related OCD to refer to what is believed to be a meaningful distinction between these subtypes of OCD. This distinction is supported by differences in sex ratio, with tic-related OCD over-represented among males [George et al., 1993; Leckman et al., 1995; Leonard et al., 1992]. The distinction between tic-related and non-tic-related OCD is also supported by data indicating an earlier age of onset for tic-related-OCD [de Groot et al., 1994; Leonard et al., 1992]. Additionally, an increased rate of OCD has been found among family members of patients with Tourette's syndrome, regardless of whether the proband had co-morbid OCD [Comings and Comings, 1987; Eapenet al., 1993; Pauls et al., 1986, 1991]. Neurobiologic differences have also been observed between these subtypes [Hanna et al., 1991].
Examining OCD symptom profiles is another method that has been used to investigate differences between tic-related and non-tic-related OCD. Rituals related to touching, tapping, rubbing, blinking, or staring appear to be more common among OCD patients with comorbid tics [Holzer et al., 1994; Leckman et al., 1995] or Tourette's syndrome [George et al., 1993; Leckman et al., 1994]. Additionally, several studies have found a lower prevalence of contamination obsessions and washing/cleaning compulsions among patients with tic-related-OCD [Baer, 1994; de Groot

Department of Psychiatry, University of Michigan, Ann Arbor, Michigan

*Correspondence to: Dr. Joseph A. Himle, Department of Psychiatry, University of Michigan Health System, 1500 East Medical Center Drive, Ann Arbor, MI 48109-0840.

E-mail: himlej@umich.edu

Received for publication 23 August 2001; Accepted 26 October 2002

Published online in Wiley InterScience (www.interscience.wiley. com). DOI 10.1002/da.10088 
et al., 1995; George et al., 1993; Holzer et al., 1994; Leckman et al., 1995].

A final method, useful in making distinctions between tic-related and non-tic-related OCD, is response to treatment. McDougle and colleagues [1994] found a selective response to fluvoxamine augmented with haloperidol among patients with ticrelated OCD. Individuals with tic-related OCD experienced significant improvement when haloperidol was added to fluvoxamine, whereas haloperidol augmentation did not result in improvement among patients with non-tic-related OCD. However, a recent study of patients with treatment resistant OCD, who were given risperidone augmentation of various serotonin reuptake-inhibiting medications, found significant improvement among both patients with tic-related and non-tic-related OCD [McDougle et al., 2000]. The conflicting results of these studies make it difficult to draw firm conclusions about differential pharmacotherapy response between tic-related and non-ticrelated OCD. No studies exist that test the differential effect of cognitive-behavioral therapy (CBT), the other primary treatment for OCD [Franklin et al., 1998; March et al., 1994; Piacentini, et al., 2002; Rachman and Hodgson, 1980], for tic-related vs. non-tic-related OCD. At least two anecdotal reports suggest tic-related OCD may not respond as well to CBT as does non-ticrelated OCD [King et al., 1998; Leckman et al., 2000]. This observation may be in part due to symptom profile differences between tic-related and non-ticrelated OCD, as noted above. Contamination/washing and doubting/checking symptoms are less common in tic-related OCD but have been shown to respond better to CBT [Buchanan et al., 1996; Drummond, 1993]. Clinical impressions would also suggest that rituals related to touching, tapping, rubbing, staring, and blinking, which are more prevalent in tic-related OCD, may be more difficult to treat with exposure and response prevention. Further research is warranted to investigate whether tic-related OCD responds differently than non-tic-related OCD to medication and/or CBT.

We present an uncontrolled clinical trial of group cognitive-behavioral therapy for adolescents with either tic-related or non-tic-related OCD.

\section{SUBJECTS AND METHODS}

Subjects were 19 adolescent patients with the diagnosis of OCD who were recruited through the child and adolescent division of the University of Michigan, Department of Psychiatry, and completed a 7 -week course of group CBT ( $\mathrm{n}=1$ dropout). Participants were drawn from the larger clinic sample $(n=52)$, and represent those study-eligible adolescents who expressed an interest in participating in group CBT, and were available during the scheduled group time. Nine of the patients (five with tic-related OCD and four with non-tic-related OCD) received an extensive diagnostic evaluation as participants in a family study of OCD. They were interviewed with the Schedule for Affective Disorders and Schizophrenia for School-Age Children-Epidemiologic Version [KSADS-E; Orvaschel, 1987]. The interview was completed independently with a parent of the patient as well as with the patient. The interview was supplemented with the sections on OCD and tic disorders from the Schedule for Tourette and Other Behavioral Syndromes [Pauls and Hurst, 1991]. The remaining 10 patients (three with tic-related OCD and seven with non-tic-related OCD) received diagnostic evaluations performed by faculty and staff clinicians (e.g., social workers, psychologists, and psychiatrists) who were well trained in the identification and diagnosis of OCD using DSM-III-R or DSM-IV criteria [American Psychiatric Association, 1987, 1994]. Tic-related OCD was defined as a current DSM-IV tic disorder diagnosis, and non-tic-related OCD required a lack of any lifetime history of tics. Altogether, eight patients had tic-related OCD and 11 had non-tic-related OCD. Patients with bipolar disorder, severe major depression, mental retardation, pervasive developmental disorder, schizophrenia, or other psychotic disorders were excluded from participating in the group. Of those expressing an interesting the group treatment, one patient was excluded due to comorbid pervasive developmental disorder.

The sample consisted of 11 boys and 8 girls. The mean age was $14.63(S D=1.71)$ years. All patients were attending either middle or high school. Mean age of OCD onset was $11.09(S D=3.26)$ years and duration of illness was $4.08(S D=3.2)$ years. Cormorbidity for both groups is presented in Table 1. Depression and other anxiety disorders were the most common comorbid disorders. Patterns of comorbidity were similar for both subtypes. Table 2 presents primary OCD symptoms for the tic-related and non-tic-related groups. Primary symptoms related to contamination/washing were more common in the non-tic-related subtype, whereas harm obsessions/compulsions were slightly more prevalent in the tic-related group. Thirteen

TABLE 1 . Lifetime cormorbidity by obsessive-compulsive disorder subtype

\begin{tabular}{lcc}
\hline & $\begin{array}{c}\text { Tic-related } \\
\text { OCD }\end{array}$ & $\begin{array}{c}\text { Non-tic-related } \\
\text { OCD }\end{array}$ \\
\hline Major depression & 4 & 3 \\
Dysthymia & 0 & 1 \\
Attention deficit-hyperactivity & 2 & 2 \\
$\quad$ Disorder & 1 & \\
Oppositional-defiant disorder & 2 & 2 \\
Separation anxiety disorder & 0 & 1 \\
Panic disorder & 0 & 1 \\
Social phobia & 1 & 1 \\
Agoraphobia & 1 & 1 \\
Specific phobia & 1 & 1 \\
Generalized anxiety disorder & & \\
\hline
\end{tabular}


patients were taking psychotropic medication at the start of the group (six with tic-related OCD and seven with non-tic-related OCD). Medications included fluoxetine (five patients), fluvoxamine (three), clomipramine (six), sertraline (one), clonidine (two), methylphenidate (two), dextroamphetamine (one), guanfacine (two), buproprion (one), and lithium (one). Medication doses were held constant from 3 weeks prior to the group through the end of the group. No individual therapy (cognitive-behavioral or otherwise) was provided during the group. Five of the patients (two ticrelated and three non-tic-related) participating in the group had previously been non-responsive to individual CBT. All medicated patients were either partially or non-responsive to OCD medication.

\section{GROUP TREATMENT}

All patients were given seven weekly, 90-minute, group CBT sessions conducted over a 2-year period [see Fischer et al., 1998, for a complete description of the group therapy format). Each of the four groups was closed-ended and included four to six patients (therapist DJF). Patients with and without tics were treated together in the same group. Treatment was designed to address OCD symptoms and not tics. The treatment program focused upon exposure and response prevention conducted in-session and through homework assignments, and also included instruction in a cognitive framework for externalizing OCD as an

TABLE 2. Primary symptoms by obsessive-compulsive disorder subtype

\begin{tabular}{lcc}
\hline & $\begin{array}{c}\text { Tic-related } \\
\text { OCD }\end{array}$ & $\begin{array}{c}\text { Non-tic-related } \\
\text { OCD }\end{array}$ \\
\hline Contamination/Washing & 2 & 5 \\
Harming Others/Repeating & 2 & 1 \\
Harming Others/Checking & 1 & 1 \\
Harm Coming to Others/Checking & 2 & 1 \\
Harm Coming to Others/Repeating & 1 & 3 \\
\hline
\end{tabular}

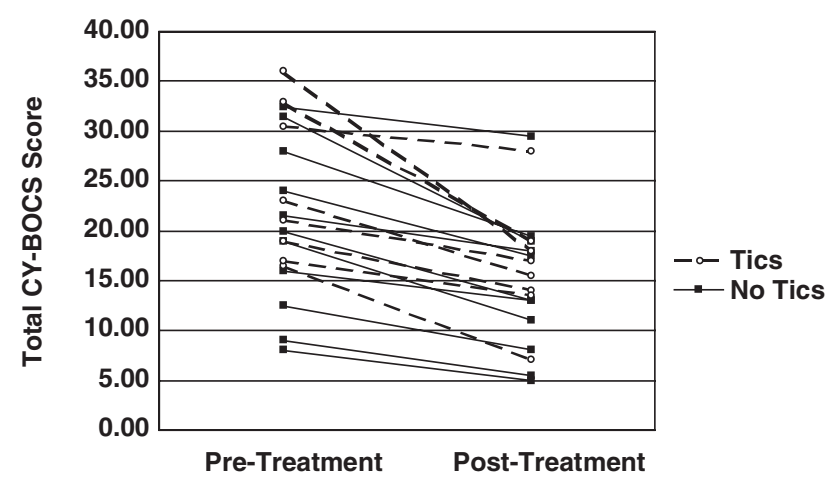

Figure 1. Pre-post treatment scores for individual subjects with tic-related vs. non-tic-related OCD. enemy to battle (following March et al., 1994), and education about the nature of OCD. Efforts were made to facilitate group cohesiveness and mutual reinforcement for treatment compliance, and to instruct members in the use of coping self-statements (e.g., "It's not me, it's my OCD"). Each session included an educational topic in addition to CBT. The six educational topics included the nature of $\mathrm{OCD}$, principles of behavioral therapy, causes of OCD, family life and OCD, specialized techniques for making CBT more effective, and lifestyles and OCD. Additionally, an optional eighth session for patients and their parents was offered. During this session, parents were educated about the nature and treatment of OCD and the group leader facilitated a discussion of OCD related family problems.

\section{MEASURES}

The Children's Yale-Brown Obsessive-Compulsive Scale [CY-BOCS; Goodman et al., 1989a,b; Scahill et al., 1997] was used to rate the severity of obsessivecompulsive symptoms at baseline and post-treatment. The CY-BOCS is a clinician rated scale that measures the severity of ten items, ranging from 0 (none) to 4 (extreme). (The 10 items are divided into two subscales: obsessions and compulsions.) CY-BOCS severity is rated as $0-7$ sub-clinical, $8-15$ mild, 16-23 moderate, 24-31 severe, and 32-40 extreme. The CY-BOCS has good face and content validity, inter-rater reliability, and a high degree of internal consistency [Scahill, et al., 1997]. Baseline and post-treatment CY-BOCS ratings were completed by trained clinicians blinded to pre versus post group status.

\section{RESULTS}

The tic-related and non-tic-related OCD groups did not significantly differ in sex ratio $(25 \%$ female ticrelated; $55 \%$ female non-tic-related; $\chi^{2}=1.659 ; d f=1$; $P=352$ ), mean age (tic-related $M s=14.25 ; S D=1.34$; non-tic-related $M s=14.91 ; S D=1.92 ; t=-.824 ; d f=17$; $P=422$ ), or initial CY-BOCS score (tic-related $M s=24.5 ; \quad S D=7.61 ; \quad$ non-tic-related $\quad M s=20.18$; $S D=8.42 ; t=1.148 ; d f=17 ; P=.267)$.

All 19 patients showed improvement in CY-BOCS scores from the beginning to the end of the group (see Fig. 1). Paired Student's $t$-tests for all subjects pooled together revealed significant improvement from the baseline $(M s=22.00 ; S D=8.17)$ to post treatment $(M s=15.32 ; S D=6.62 ; t=6.78 ; d f=18 ; P<.0001)$. Significant improvement in CY-BOCS obsession subscores were also observed from baseline $(M s=10.61$; $S D=4.12)$ to post-treatment $(M s=8.11 ; S D=3.27$; $t=4.06 ; d f=18 ; P=.001)$. Finally, CY-BOCS compulsion sub-scores improved from the beginning $(M s=11.39$; $S D=4.26)$ to the end of the group $M s=7.21(S D=3.54$; $t=9.08 ; d f=18 ; P<.0001)$. Outcome was not significantly affected by medication status for the overall sample ( $d f=17 ; t=.291 ; P=.774)$ nor for the tic-related 
$(d f=6 ; t=1.04 ; P=.84)$ nor non-tic-related subtypes $(d f=9 ; t<0.001 ; P=.99)$.

Repeated measures analysis of variance was performed to compare differences in treatment response between tic-related and non-tic-related OCD from baseline to post-treatment. No significant tic group by time interaction for total CY-BOCS scores was observed from baseline to post-treatment between the tic-related and non-tic-related groups $(\mathrm{F}=1.32 ; d f=1$, $17 ; P=.27)$. Similarly, differences were not statistically significant across tic groups from baseline to posttreatment for obsession scores $(\mathrm{F}=0.26 ; d f=1,17$; $P=62)$ or compulsion scores $(\mathrm{F}=3.44 ; d f=1,17$; $P=08)$.

\section{DISCUSSION}

Although clearly preliminary, the findings of this uncontrolled trial of group CBT for adolescent patients with tic-related and non-tic-related OCD suggest that the distinctions between these groups may not extend to differential response to CBT treatment. Similar CBT outcomes were obtained despite the expected increased prevalence of contamination/washing symptoms among the non-tic-related group. Symptom profiles between tic-related and nontic-related OCD are likely to differ, but those differences may not influence CBT outcomes. Additionally, the similar comorbidity patterns observed between the tic-related and non-tic-related groups suggest that CBT outcomes were not unduly altered by these comorbid conditions.

The finding of similar CBT outcomes between ticrelated and non-tic-related OCD is especially noteworthy, given conflicting results regarding response to pharmacotherapy found among patients with ticrelated and non-tic-related OCD [McDougle et al., 1994, 2000]. The results of this study also run counter to clinical impressions that tic-related OCD does not respond as well to CBT [King et al., 1998; Leckman et al., 2000].

If confirmed in future research with a larger sample size, the comparable response to behavioral treatment between tic-related and non-tic-related OCD would be somewhat surprising in light of the distinctive phenomenological (early onset) [de Groot et al., 1995; Leonard et al., 1992], neurobiological [Hanna et al., 1991], and family data [Comings and Comings, 1987], suggesting that these OCD subtypes differ in certain aspects of their pathophysiology. It has been suggested that tic-related OCD is complicated by a dopaminergic dysfunction that compromises the response to monotherapy with serotonergic antidepressants [McDougle et al., 1994]. Despite these differences, the results of this study suggest that comorbid tic disorders may not attenuate the response to group CBT among adolescents with OCD.

Methodological limitations of this study suggest that these results should be interpreted with some caution.
The small sample size and the resulting limited statistical power increase the risk of type-II error. However, it is important to note that the amount of improvement from baseline to post-treatment was actually greater in the tic-related group compared to the non-tic-related group, although this difference was not significant. Sex ratio differences between the two groups may have influenced treatment outcome but it is important to note that the higher prevalence of males in the tic-related group is typical of this subtype [Geller et al., 1998]. Additionally, it is possible that the comparable treatment response observed in both the tic-related and non-tic-related groups was in part due to a floor effect created by inclusion of two subjects with particularly low baseline CY-BOCS scores in the non-tic-related group (total CY-BOCS $<10$ ). However, excluding these subjects from analyses did not alter the finding of non-significance in treatment response between the two subgroups under study. Second, this study was an uncontrolled clinical trial, making it possible that a portion of the treatment effect may be due to non-specific factors. However, there is no reason to anticipate that the tic-related and non-ticrelated subtypes would have responded differentially to placebo effects, thus limiting the likelihood that the absence of a control group posed a notable confound in the current investigation. Third, the study lacks a measure of tic severity, which may influence treatment outcome for subjects with tic-related-OCD, although it is important to note that the sample size in the present study would not have had sufficient statistical power to detect subgroup differences even if these measures were available. Finally, assessment of changes in tic severity over the course of the group and use of structured diagnostic interviews for all subjects would have enhanced the methodological rigor of this study. Methodological strengths of the study, however, include the use of a manualized treatment program, psychometrically sound outcome measures, and blind independent ratings of progress.

The discussed shortcomings notwithstanding, it appears in this small sample of adolescents that group CBT is effective for both tic-related and non-tic-related OCD. The present results stand as the only data that examine the differential response to CBT among subjects with these OCD subtypes. These preliminary results stand in contrast to the clinical impression that tic-related OCD responds less well to CBT [King et al., 1998; Leckman et al., 2000]. Further research using a control group and other methodological improvements is needed to confirm these findings.

\section{REFERENCES}

American Psychiatric Association. 1987. Diagnostic and statistical manual, 3rd edition, revised. Washington, DC: American Psychiatric Association. 
American Psychiatric Association. 1994. Diagnostic and statistical manual, 4th edition. Washington, DC: American Psychiatric Association.

Baer L. 1994. Factor analysis of symptom subtypes of obsessivecompulsive disorder and their relation to personality and tics. J Clin Psychiatry 55:18-23.

Buchanan AW, Meng KS, Mark IM. 1996. What predicts improvement and compliance during the behavioral treatment of obsessive compulsive disorder? Anxiety 2:22-27.

Comings DE, Comings BG. 1987. A controlled study of Tourette syndrome. IV. Obsessions, compulsions, and schizoid behaviors. Am J Hum Genet 41:782-803.

de Groot CM., Bornstein RA, Janus MD, Mavissakalian MR. 1995. Patterns of obsessive-compulsive symptoms in Tourette subjects are independent of severity. Anxiety 1:268-274.

Drummond LM. 1993. The treatment of severe, chronic, resistant obsessive compulsive disorder: an evaluation of an in-patient program using behavioral psychotherapy in combination with other treatments. Br J Psychiatry 163:223-229.

Eapen V, Pauls DL, Robertson MM. 1993. Evidence for autosomal dominant transmission in Tourette's syndrome-United Kingdom cohort study. Br J Psychiatry 162:593-596.

Fischer DJ, Himle JA, Hanna GL. 1998. Group behavioral therapy for adolescents with obsessive-compulsive disorder: preliminary outcomes. Res Soc Work Pract 8:629-636.

Franklin ME, Kozak MJ, Cashman LA, Coles ME, Rheingold AA, Foa EB. 1998. Cognitive-behavioral treatment of pediatric obsessive-compulsive disorder: an open clinical trial. J Am Acad Child Adolesc Psychiatry 37:412-419.

Geller DA, Biederman J, Jones J, Park K. Schwartz S. Shapiro S, Coffey B. 1998. Is juvenile obsessive-compulsive disorder a developmental subtype of the disorder? A review of the pediatric literature. J Am Acad Child Adolesc Psychiatry 37:420-427.

George MS, Trimble MR, Ring HA, Sallee FR, Robertson MM. 1993. Obsessions in obsessive-compulsive disorder with and without Gilles de la Tourette's syndrome. Am J Psychiatry 150:93-97.

Goodman WK, Price LH, Rasmussen SA, Mazur, C, Fleischmann RL, Hill CL, Heninger GR, Charney DS. 1989a. The Yale-Brown Obsessive Compulsive Scale I. Development, use, and reliability. Arch Gen Psychiatry 46:1006-1011.

Goodman WK, Price LH, Rasmussen SA, Mazure C, Delgado P, Heninger GR, Charney DS. 1989b. The Yale-Brown Obsessive Compulsive Scale II: validity. Arch Gen Psychiatry 46:1012-1016.

Hanna GL, McCracken JT, Cantwell DP. 1991. Prolactin in childhood obsessive-compulsive disorder: clinical correlates and response to clomipramine. J Am Acad Child Adolesc Psychiatry 30:173-178.

Holzer J, Goodman WK, McDougle CJ, Baer L, Boyarsky BK, Leckman JF, Price LH. 1994. Obsessive compulsive disorder with and without a chronic tic disorder: a comparison of symptoms in 70 patients. Br J Psychiatry 164:469-473.

King RA, Leonard H, March JS. 1998. Practice parameters for the assessment and treatment of children and adolescents with obsessive-compulsive disorder. J Am Acad Child Adolesc Psychiatry $37: 27 \mathrm{~S}-45 \mathrm{~S}$.

Leckman JF, Goodman WK, North WG, Chappell PB, Price LH, Pauls DL, Anderson GM, Riddle MA, McSwiggan-Hardin M, McDougle CJ, Barr LC, Cohen DJ. 1994. Elevated levels of CSF oxytocin in obsessive compulsive disorder: comparison with Tourette's syndrome and healthy controls. Arch Gen Psychiatry 51:782-783.

Leckman JF, Grice DE, Barr LC, deVries ALC, Martin C, Cohen DJ, Goodman WK, Rasmussen SA. 1995. Tic-related vs. non-ticrelated obsessive compulsive disorder. Anxiety 1:208-215.

Leckman JF, McDougle CJ, Pauls DL, Peterson BS, Grice DE, King RA, Scahill L, Price LH, Rasmussen SA. 2000. Tic-related versus non-tic-related obsessive-compulsive disorder. In: Goodman WK, Rudorfer MV, Maser JD, editors. Obsessive-compulsive disorder: contemporary issues in treatment. Mahwah, NJ: Lawrence Erlbaum Associates, Inc. p 43-68.

Leonard HL, Lenane MC, Swedo SE, Rettew DC, Gershon ES, Rapoport JL. 1992. Tics and Tourette's Disorder: A 2- to 7-year follow-up of 54 obsessive-compulsive children. Am J Psychiatry 149:1244-1251.

March JS, Mulle K, Herbel B. 1994. Behavioral psychotherapy for children and adolescents with obsessive-compulsive disorder: an open trial of a new protocol-driven treatment package. J Am Acad Child Adolesc Psychiatry 33:333-341.

McDougle CJ, Goodman WK, Leckman JF, Lee NC, Heninger GR, Price LH. 1994. Haloperidol addition in fluvoxamine in obsessivecompulsive disorder: a double blind placebo-controlled study in patients with and without tics. J Clin Psychopharmacol 51:302308.

McDougle CJ, Epperson CN, Pelton GH, Wasylink S, Price LH. 2000. A double blind, placebo controlled study of risperidone addition in serotonin reuptake inhibitor-refractory obsessivecompulsive disorder. Arch Gen Psychiatry 57:794-801.

Orvaschel H. 1987. Schedule for affective disorders and schizophrenia for school aged children-epidemiologic version (K-SADSE), 4th edition. Philadelphia, PA: Medical College of Pennsylvania.

Pauls DL, Towbin KE, Leckman JF, Zahner GEP, Cohen DJ. 1986. Gilles de la Tourette's syndrome and obsessive-compulsive disorder. Arch Gen Psychiatry 43:1180-1182.

Pauls DL, Hurst CR. 1991. Schedule for Tourette and other behavioral symdromes (adult on child form, version C1. New Haven: Child Study Center, Yale University School of Medicine.

Pauls DL, Raymond CL, Leckman JF, Stevenson JM. 1991. A family study of Tourette's syndrome. Am J Hum Genet 48:154-163.

Piacentini J, Bergman RL, Jacobs C, McCracken JT, Kretchman J. 2002. Open trial of cognitive behavior therapy for childhood obsessive-compulsive disorder. J Anxiety Disorders 16:207-219.

Rachman S, Hodgson R. 1980. Obsessions and compulsions. Englewood Cliffs, NJ: Prentice Hall.

Scahill L, Riddle MA, McSwiggin-Hardin MT, Ort S, King RA, Goodman WK, Cicchetti D, Leckman JF. 1997. The Children's Yale-Brown Obsessive-compulsive Scale: preliminary report of reliability and validity. J Am Acad Child Adolesc Psychiatry 36:844-853. 